\title{
Impact of Paneth Cell Autophagy on Inflammatory Bowel Disease
}

\author{
Shu-Ling Wang ${ }^{1 \dagger}$, Bo-Zong Shao ${ }^{2 \dagger}$, Sheng-Bing Zhao ${ }^{1 \dagger}$, Jun Fang ${ }^{3}$, Lun Gu ${ }^{1}$, \\ Chao-Yu Miao ${ }^{2 *}$, Zhao-Shen $\mathrm{Li}^{1 *}$ and Yu Bai ${ }^{*}$ \\ 'Department of Gastroenterology, Changhai Hospital, Second Military Medical University and Naval Medical University, \\ Shanghai, China, ${ }^{2}$ Department of Pharmocology, Second Military Medical University and Naval Medical University, \\ Shanghai, China, ${ }^{3}$ Department of Gastroenterology, Zhongnan Hospital of Wuhan University, Wuhan, China
}

Intestinal mucosal barrier, mainly consisting of the mucus layer and epithelium, functions in absorbing nutrition as well as prevention of the invasion of pathogenic microorganisms. Paneth cell, an important component of mucosal barrier, plays a vital role in maintaining the intestinal homeostasis by producing antimicrobial materials and controlling the host-commensal balance. Current evidence shows that the dysfunction of intestinal mucosal barrier, especially Paneth cell, participates in the onset and progression of inflammatory bowel disease (IBD). Autophagy, a cellular stress response, involves various physiological processes, such as secretion of proteins, production of antimicrobial peptides, and degradation of aberrant organelles or proteins. In the recent years, the roles of autophagy in the pathogenesis of IBD have been increasingly studied. Here in this review, we mainly focus on describing the roles of Paneth cell autophagy in IBD as well as several popular autophagy-related genetic variants in Penath cell and the related therapeutic strategies against IBD.

Keywords: autophagy, Paneth cell, inflammatory bowel disease, unfolded protein response, endoplasmic reticulum stress

\section{INTRODUCTION}

The intestinal tract functions in digesting food taken orally and absorbing nutrients from the materials in the gut lumen. Apart from this, the gut is also considered as a crucial immune organ due to the enormously diverse microorganism harbored in the gut. During this process, intestinal mucosal barrier plays a pivotal role in maintaining the peaceful coexistence with them, detecting, and eliminating the pathogenic microbial debris by triggering immune response and inflammatory reaction (1-5). In general, the intestinal defense system is composed of three parts, including the mucus layer, intestinal epithelial cells (IECs), as well as other cells related to the innate immune system (6). However, once the intestinal mucosal barriers are damaged or the microbial balance is disturbed, the immune and inflammatory responses will be over-activated, along with the accumulation of the reactive oxygen species (ROS) and disturbance of mitochondrion in function $(7,8)$. Those responses may contribute to the pathogenesis of inflammatory bowel disease (IBD) (9). Consequently, inhibiting the over-triggered inflammatory and defensive responses may serve as a potential and effective treatment for IBD. Among all of IECs, Paneth cells were reported to play a vital role in regulating the microbial composition, the innate and adaptive immune responses to the host, and the inflammatory reaction $(10-12)$. Autophagy is a self-protecting response to various stresses, which plays a pivotal role in physiological processes, such as secreting proteins, producing antimicrobial peptides (AMPs) and degrading aberrant organelles or proteins, and thus easing 


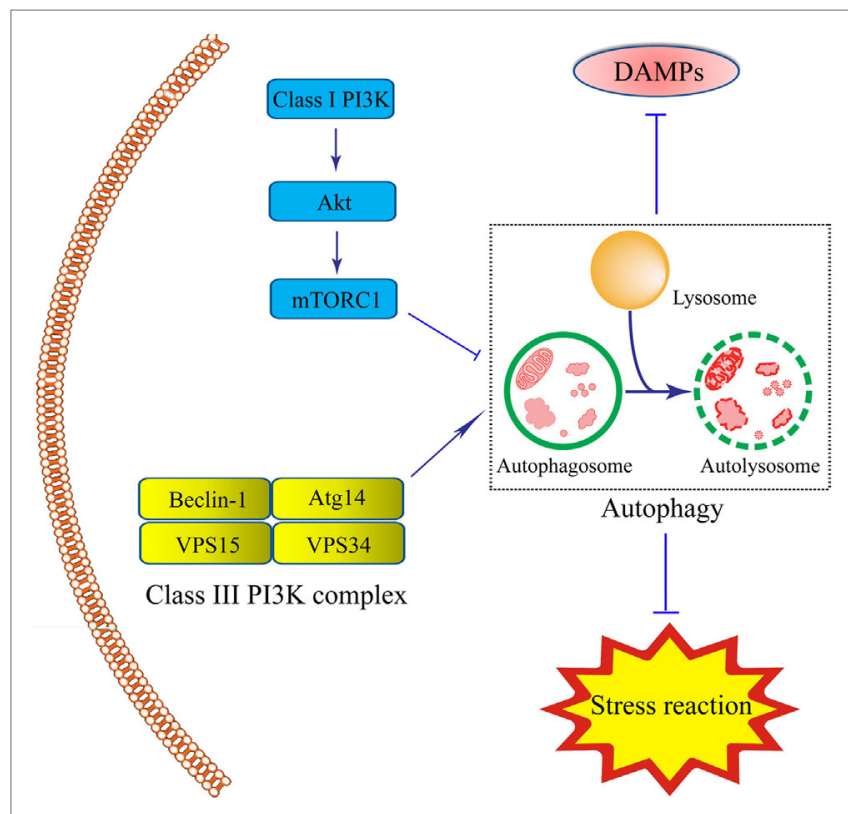

FIGURE 1 | Schematic illustration of roles of intestinal epithelial cells (IEC) autophagy in the prevention of inflammatory bowel disease (IBD). Autophagy process in IECs is induced under inflammation- or immune-related challenge by the formation of the double-membrane autophagosomes. The integrity of autophagosomes and lysosomes leads to the formation of the singlemembrane autolysosomes, functioning in degrading and recycling misfolded proteins, or dysfunctional organelles, thus contributing to cellular protection. The Class III-PI3K-Beclin-1 signaling pathway, led to the formation of Class III complex (Beclin-1-Atg14-vacuolar protein sorting(VPS)15-VPS34 complex) is the major inductive pathway to autophagy process, while the Class I-PI3K-mammalian target of rapamycin signaling pathway led to the inhibitory effects on autophagy process. The induction of autophagy protects IECs under stress through the degradation of various kinds of the damageassociated molecular pattern molecules and suppression of stress reaction.

the over-activated inflammation and self-defensive responses (13-15). Dysfunction of autophagy is regarded as a vital factor in the pathogenesis of IBD, which may be related to the impairment of the bacterial killing, antimicrobial materials secretion, and so on. Given those evidence, an increasing number of researches are focusing on the role of autophagy in developing a novel therapeutic strategy to fight against inflammation or immune-related diseases, including IBD. Here, in this review, we summarized the current understanding of IBD and autophagy and most importantly, the roles of Paneth cell autophagy in IBD as well as several autophagy-related genetic variants in Paneth cell and therapeutic strategies against IBD.

\section{INTESTINAL DEFENSE SYSTEM AND IBD}

\section{Intestinal Defense System}

It is widely acknowledged that the intestinal tract is exposed to trillions of harmful antigens in food, factors derived from commensal and pathogenic microorganisms, as well as immune signals which is underneath the epithelium $(1,2,16,17)$. As a result, the intestinal defense system plays a significant role in

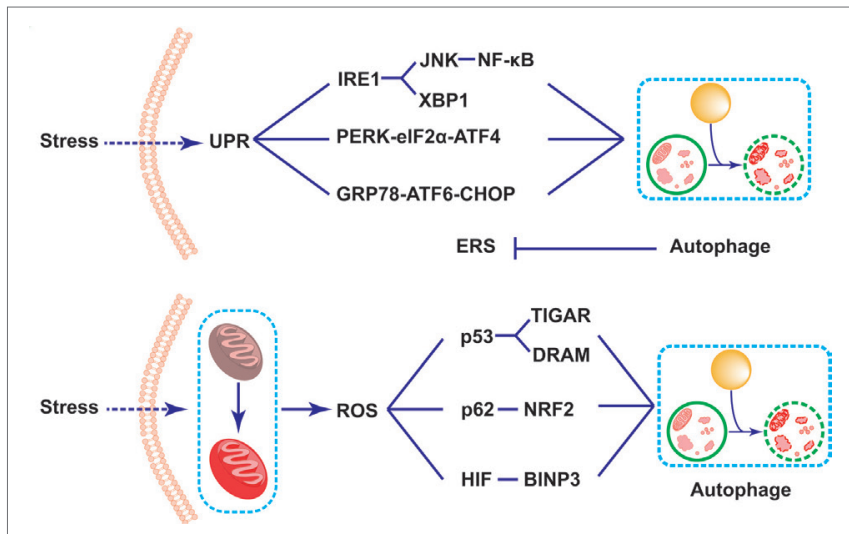

FIGURE 2 | Schematic illustration of mechanisms of Paneth cell autophagy related to endoplasmic reticulum stress (ERS) and reactive oxygen species (ROS) in inflammatory bowel disease alleviation. Under the challenge of stresses, the triggering of the self-protected unfolded protein response process leads to the induction of ERS in Paneth cells. The ERS subsequently results in the induction of autophagy through three signaling pathways, including IRE1-JNK/NK-кB/XBP1, pancreatic ER kinase-elF2d-activated transcription factor 4, and GRP78-activated transcription factor 6-CHOP signaling pathways. The induction of autophagy thus reduces the overtriggering of the ERS. In addition, the mitochondrial dysfunction triggers the accumulation of the reactive oxygen species (ROS) in Paneth cells. The triggering ROS largely induces autophagy process through the p53-TIGAR/ damage-regulated autophagy modulator, p62-NF-E2-related factor 2, as well as BINP3 pathways, thus fighting against cellular damage under stresses.

maintaining the homeostasis between the host and microbial community. Generally speaking, various kinds of proteins, lipids, and carbohydrates accumulate in water, forming a gel-like layer on the surface of mucosa in the intestinal mucus layer $(18,19)$. The mucus layer underneath is composed of two layers: the outer and inner layers $(6,20)$. Among all of components in the mucus layer, the AMPs, such as defensins and cathelicidins, protect the intestinal tract against microbes $(21,22)$. When pathogens intrude, mucus layers work together with IECs to form a physical and chemical barrier, generating various inflammatory responses and immune reaction via various specific and unspecific mechanisms (23). Apart from the mucus layers, IECs also form a central part of the intestinal defense system which work as an interface between the quantitative microbial ecosystem in the intestinal lumen and the relatively sterile environment of the internal body (3-5). Specifically speaking, the epithelium mainly consists of six types of IECs, including goblet cells, enteroendocrine cells, absorptive enterocytes, tuft cells, micro-fold villus cells, and Paneth cells (24). Goblet cells mainly secrete a great amount of mucin to build up the mucus barrier, while the enteroendocrine cells help to produce various neuropeptides and restore the intestinal tissue $(25,26)$. As the most abundant cell type, absorptive enterocytes secret a series of cytokines and chemokines, which play a pivotal role in regulating the diversity of the commensal microorganisms and the immune responses of subjacent mucosal (27). Paneth cells, first described by an Austrian physiologist called Joseph Paneth, initially located at the bottom of small intestinal crypts, are the key cells in this review for discussion. Paneth cells secret granules containing various 
AMPs and peptides, such as defensins-like human lysozyme, defensin (HD)-5 and -6, lysozyme, regenerating islet-derived 3 gamma (RegIII $\gamma$ ) and phospholipase A2 group IIA (sPLA2), as well as inflammatory cytokines, such as transforming tumor necrosis factor $\alpha$ (TNF- $\alpha$ ), growth factor $\beta 1$ (TGF- $\beta 1$ ), and prostaglandin E2 (28-34). Previous studies demonstrated the crucial roles of Paneth cells in fighting against the invasion of pathogens, modulating the commensal microbiota, regulating the innate immunity, as well as impacting the functions of intestinal niche (7, 8, 31, 35-39). Those studies will be described and discussed in detail in the following part of the contents.

\section{Pathogenesis of IBD}

Generally speaking, IBD is mainly composed of two types, namely Crohn's disease (CD) and ulcerative colitis (UC). CD is remarkable for skipping and transmural inflammation in the distal small intestine and colon with lymphoid aggregation. In terms of UC, the inflammatory areas are continuously extending from the rectum to the whole colon and the inflammation mainly confines to the mucosa and are featured by a mixture of various inflammatory cells. Recent reports demonstrated that IBD affected nearly 1.5 million people in America and led to major morbidity, especially among young people $(40,41)$.

Although the precise etiology of IBD remains to be unclarified, increasing evidence suggests that genetic, environment, and interactions between intestinal barriers and commensal microbiota may converge to trigger the initiation and progression of IBD (42). Epidemiological data provides evidence for the role of gene in the development of IBD: $15 \%$ of patients with CD would have an IBD-affected family member, and the concordance of CD in monozygotic twins is up to $59 \%$ which is much higher than in the dizygotic twins (only 10\%) (43). Genome-wide association studies (GWAS) have recognized over 200 IBD susceptibility loci, which will be discussed in the subsequent contents of the review $(44,45)$. Besides, accumulating studies implicated various pathways in the development of IBD, including the modulation of the intestinal microbiota, over-triggered inflammation, abnormal innate or adaptive immune reaction, and endoplasmic reticulum stress (ERS) (46-48). In addition, environmental factors also play an important role in the onset and development of IBD and smoking is considered as a crucial environmental risk for the development of CD (49). Another environmental factor contributing to IBD is air pollution (50). It was reported that ozone or nitrous oxides could intrude into intestinal tract through food and water, increasing the permeability of IECs (51). Besides, a clinical study conducted by Larsson et al. showed that the mucin 2 was deficient in the majority of the active UC patients, which was associated with the severity of IBD (52). In addition, it was also reported that dysfunction of the immune reaction contributed to the pathogenesis and progression of IBD through the dysregulation of the IFN- $\gamma /$ STAT1 pathway as well as the imbalance of Treg and Th17 cells in IBD $(53,54)$. Among various intestinal defense systems, the dysfunction of Paneth cells may be a crucial factor attributing to IBD by reducing the production of the antibacterial peptides and changing the diversity and quantity of intestinal microbiota. Furthermore, microbial profiling studies also have demonstrated the important role of dysbiosis in IBD onset (55). Although no causative microbe has yet been identified, plenty of evidence has focused on the expansion of opportunistic pathogens ("pathobionts"), such as adherent-invasive Escherichia coli strains (AIEC) (56). Finally, some special drugs, such as antibiotics was also a potential factor in the pathogenesis of IBD because antibiotics could alter the intestinal microbiota (57).

\section{AUTOPHAGY AND IBD}

\section{Autophagy and Its Functions}

Autophagy is a conserved lysosome-dependent catabolic process, degrading and recycling protein aggregates and damaged organelles (58). Basal autophagy occurs in nearly all kinds of cells to maintain the homeostasis of amino acid pool (59). Autophagy is generally classified into three types: macroautophagy, microautophagy, and chaperone-mediated autophagy $(60,61)$. During the process of microautophagy, lysosomal/ vacuolar membranes invaginate so as to engulf intracellular components via a non-selective degradative mechanism (62). It was reported previously that chaperone-mediated autophagy could transport organelles and proteins into lysosomes only with the assistance of chaperones which were located in the lysosomal lumen (63). In the occurrence of macroautophagy, target materials, such as cytoplasmic components or invasive bacteria are surrounded by a double-membrane bound autophagosome. When autophagosome was combined with lysosome, it changes into a single-layer-membrane autolysosome with a strong degradative and digestive ability (64). Since macroautophagy is the most studied type, we will mainly explore the functions and roles of macroautophagy (hereafter referred to as "autophagy") in IBD.

There are two steps involved in the process of autophagy. In the first step, the cup-shaped double-membrane phagophores are shaped in the cytoplasm, and then engulf misfields proteins, damaged organelles or bacteria to become spherical doublemembraned autophagosomes. Autophagosomes are usually considered to be produced from the nucleation and membrane expansion of phagophores. During the second step, autophagosomes fuse with lysosomes and endosomes to form the singerlipid layer autolysosome, which is regarded as basal units for degradation and digestion (65). Autophagy process is induced by the detection of various specific cues, such as starvation or the invasion of microbes $(66,67)$. So far, two proteins are involved in the regulation of autophagy, including the mammalian target of rapamycin (mTOR) as an inhibitor and adenosine monophosphate-activated protein kinase as an inductor (65). The mTOR is often activated by lower levels of adenosine triphosphate (ATP) caused by nutrient sufficiency or several growth factors stimulation. It is triggered by the activation of Class I PI3K-mTOR via the phosphorylation of Akt pathway and formation of mTOR complex-1. This complex prevents the formation of autophagosome by inhibiting Atg1 $(66,68)$. The inductive signaling pathway is usually triggered when there is deficient nutrition, inflammation, or ROS stress. In this process, the Class III PI3K complex is formed by Beclin-1, Atg14, vacuolar protein sorting (VPS)15, 
and VPS34, leading to the assembly of the Atg12-Atg5-Atg16L complex and Atg8/LC3. Initiation of this signaling pathway plays a significant role in forming autophagosomes (Figure 1).

So far, increasing studies have demonstrated the crucial role of autophagy in maintaining cell and tissue homeostasis by regulating various physiological processes, including the clearance of pathogen, presentation of antigen, formation of cytokines, inflammatory responses, and the innate and adaptive immune reaction $(61,69,70)$. Autophagy is widely regarded as a vital regulator in various kinds of diseases (71). Among all the diseases, the interaction between autophagy and IBD has been extensively explored and will be discussed in the following contents.

\section{Roles of Autophagy in IBD}

As we mentioned above, IBD is a chronic and idiopathic inflammatory disease related to the over-triggering of inflammatory and immune responses in the gut (41). Autophagy affects the pathogenesis of IBD in multiple ways, including clearance of invading pathogens, secretion of antimicrobial materials from Paneth cells, presentation of antigen, and pro-inflammatory cytokine production by macrophages. One of the most important processes was to modulate the clearance of intestinal pathogenic microbes via the innate immune responses (72). When pathogens invade into the host cells, cytoplasmic vesicles in cellular plasma envelope them to form autophagosomes, thus confining them by absorbing nutrients and encouraging the acidification of micro-environment. The enhancement of autophagy promotes the combination between autophagosome and lysosome, contributing to the degradation of intracellular pathogens (also termed as xenophagy), such as Listeria and tuberculosis (73-75).

In addition, autophagy was reported to promote the survival of various cells, including IECs and neutrophils, through protecting from microbial toxins (74). It was reported that impaired autophagy could disturb the function of IECs and influence the inflammatory and immune responses, ROS production, and ERS, thus ultimately promoting the occurrence and development of IBD (76-79). Furthermore, it is noted that autophagy plays a vital role in the degradation of the damage-associated molecular pattern molecules (DAMPs), contributing to the alleviation of IBD. In general, DAMPs refer to various kinds of endogenous materials produced by stressed, impaired, dying or dead cells, covering the DNA, RNA, ATP, histones, hyaluronan, uric acid, heparin sulfate, the S100A calgranulins, interleukin (IL)-1 family members, heat shock proteins, and chromatin-associated high-mobility group box 1 (HMGB1) (80, 81). Previous studies demonstrated that the levels of DAMPs in serum fecal or mucosa of IBD patients or animal models were elevated significantly (82-84). Although autophagy was reported to enhance the degradation of DAMPs (85), it is worth mentioning that the induced autophagy in certain cases like starvation will greatly promote the release of DAMPs, such as ATP and HMGB1 $(86,87)$. As a result, to ultimately take advantage of the inhibitory effects of autophagy on DAMPs, further studies are demanded in this issue.

\section{PANETH CELL, IBD, AND AUTOPHAGY}

\section{Paneth Cells and IBD}

As noted above, the mucus layer and IECs build up a physical and chemical barrier to prevent the invasion of pathogenic microbes, coexisting with commensal and beneficial microorganisms to maintain the homeostasis in the gut. In Paneth cells, they contain a great amount of secretary granules storing various AMPs, including HD-5, HD-6, lysozyme, RegIII $\gamma$, and sPLA2, which largely influence the intestinal inflammatory and immune responses (11, 88-92). A recent study reported that Paneth cells were an original site for intestinal inflammation, such as IBD, which could regulate inflammatory reactions via the release of AMPs and other peptides, including IgA, lysozyme, phospholipase A2 and $\mathrm{B}$, matrix metalloproteinase-7, lipopolysaccharide-binding protein, and several inflammatory cytokines (11, 93-95). AMPs are regarded as the most important antimicrobial substances in mucus layer by modulating the diversity and quantity of the intestinal microbiota and clear the invading pathogens (21). One of the most important AMPs is lysozyme, which is mainly produced by Paneth cells. The function of lysozyme is to fight against Gram-positive bacteria by catalyzing the hydrolysis of the $\beta(1,4)$-glycosidic linkages between $N$-acetylmuramic acid and $\mathrm{N}$-acetylglucosamine in the polysaccharide component (28). Besides, the production of defensin, another vital AMP, would be triggered when pathological microbes stimulated toll-like receptors and intracellular sensors, such as NOD2 and NODlike receptor (NLRs), and the mutation of NOD2 might increase the susceptibility to Crohn's disease due to the lack of defensins $(29,30)$. Several studies on human tissue or animal models have revealed the reduced level of $\alpha$-defensins in Paneth cells and the consequently decreased antimicrobial activity, which was regarded as key pathogenic factors of ileal CD $(31-33,96)$. RegIII $\gamma$ also played a key role in killing the Gram-positive bacteria by binding to cell wall peptidoglycans and loss of the antimicrobial RegIII $\gamma$ in mice contributed to spontaneous colitis (33). In addition, some researchers found that RegIII $\alpha$ could alter the colonic microbiota by decreasing the level of ROS (97). Furthermore, PLA2 released from Paneth cells also has antibacterial activity, particularly against Gram-positive and Gram-negative pathogens by releasing arachidonic acid (34).

\section{Mechanism of Paneth Cell Autophagy in IBD Alleviation}

As we discussed above, several mechanisms in Paneth cells contribute to the pathogenesis and progression of IBD. It has been reported that autophagy process in Paneth cells plays an important role in the alleviation of IBD through the regulation of several mechanisms related to IBD, such as ERS, ROS, and intestinal microbiota, which will be discussed in the following contents in detail.

\section{ENDOPLASMIC RETICULUM STRESS}

It is well known that the unfolded protein response (UPR) plays an important role in the survival and functions of IECs in the 
production of proteins, which needs accurate management of endoplasmic reticulum (ER) $(98,99)$. The dysfunction of ER resulting from either genes or environmental factors causes abnormal UPR in the ER lumen, which is called ERS $(35,100)$. As Paneth cells are one type of secretory IECs which produce and release AMPs, they are particularly prone to ERS $(98,101,102)$. Specifically speaking, ERS activates three kinds of protein residing in ER membrane to detect the UPR in ER lumen and resolve them: inositol-requiring transmembrane kinase endonuclease 1 (IRE1) via IRE1-JNk/nuclear factor-kappa B(NF-kB)/XBP1 signaling pathway, pancreatic ER kinase (PERK) via PERK-eIF2 $\alpha$ activated transcription factor (ATF) 4 signaling pathway, and activated transcription factor 6 (ATF6) via GRP78-ATF6-CHOP signaling pathway (103-106). Selected gene deletion of one of these mediators in IECs will change the histological structure of the intestinal epithelium. For example, the XBP1-deleted IECs exhibit impaired Paneth cells, and thus leads to the dysbiosis and spontaneous intestinal inflammation mimic IBD, which may be probably induced by the activation of NK- $\mathrm{KB}$ pathway $(89,91,94,98)$. The second ERS-related IBD risk gene product, orosomucoid-like 3, is located in ER membrane, and takes part in protein folding and regulating UPR (107). Researchers argued that ERS-induced inflammation in Paneth cells possibly disturbed the microbial homeostasis, thus contributing to the pathogenesis and progression of IBD (98). Recent data showed that ERS could initiate the autophagy in Paneth cells via various pathways. Some argued that the induced process depended upon IRE1 by activating TRAF2 and ultimately JNK signaling $(105,108)$. Previous studies demonstrated that ERS could induce autophagy through the PERK-eIF2 $\alpha$-ATF4 pathway or IRE1-JNK pathway, which would ease NF- $\kappa B$ signaling pathway and relieve the ERS-induced inflammation in the intestine (108-111) (Figure 2). In addition, it was reported that dysfunctional autophagy in genomic manner significantly led to the over-triggering of ERS in experimental colitis animal model as well as IBD patients, thus largely exacerbating the severity of $\operatorname{IBD}(112,113)$. For example, some researchers found that the number of Paneth cells in intestinal organoids lacing ATG16L1 was decreased, which might be related to the disruption of mitochondrial homeostasis (114). What is more, Bel et al. discovered an important role of secretory autophagy in maintaining host defense, and further showed the mechanisms how autophagy-related genes predisposed individuals to IBD. In this study, they found that ERS induced by the invasion of pathogens could trigger the secretory autophagy in Paneth cells, thus limiting bacterial dissemination (36). That study has been subsequently commented that secretory autophagy produced a vital effect on the secretion of lysozyme during bacterial infection of the gut $(115,116)$. Based on that evidence, taking advantage of autophagy process in the inhibition of ERS might serve as a potential therapy in the treatment of IBD.

Autophagy has been reported to inhibit the level of ERS in various inflammatory and immune diseases (117-119). In the pathogenesis of IBD, it was previously demonstrated that in experimental colitis mice model, the alleviative effects of TREM-1 on IBD severity was caused by the induction of autophagy and inhibition of ERS level (119). In addition, it was also demonstrated that dysfunction of autophagy resulted in the triggering of ERS in enterocytes, thus deteriorating the severity of IBD (118). A recent study showed that defective autophagy in IECs might predispose people to IBD via the decreased clearance of IRE1 during ERS (120). Those studies indicated the anti-ERS effect of autophagy in IBD.

\section{REACTIVE OXYGEN SPECIES}

In addition, ROS is considered as conservational signaling molecules in nearly all cells, which plays a vital role in modulating cellular functions (121). Under normal conditions, ROS produces during the process of oxidative phosphorylation can be handled by intracellular antioxidants. However, once the production of ROS exceeds the generation of antioxidants, it may lead to various inflammatory disease including $\operatorname{IBD}(83,122)$. As one of the most important source of ROS, dysfunctional mitochondria may modify the rearrangements of cytoskeleton, the framework of plasmalemma as well as the balance between kinases and phosphatases, thus promoting the internalization of microorganism and contributing to the onset of IBD (123). Furthermore, previous studies demonstrated the pivotal role of extracellular ROS in increasing the permeability of intestinal epithelial (124). For example, it was reported that mitoTEMPO, an antioxidant in mitochondrial, attenuated the severity of colitis induced by dextran sulfate sodium (DSS) through improving the function of the intestinal defense system (125).

The connection between autophagy and ROS has been increasingly studied recently in various kinds of diseases, including malignant tumors, neural disorders, metabolic diseases, as well as inflammation- and immune-related diseases, such as the colorectal cancer, chronic pancreatitis, and cardiologic disease (126-128). It has been demonstrated that the accumulation of ROS lead to the induction of autophagy (129). Although the specific mechanisms are not fully elucidated, the transcriptional regulatory mechanism is considered to be dominant (130). Generally speaking, several signaling pathways have been clarified. The first pathway is related to the increasing production of p53, which subsequently leads to the enhancement in transcription of two autophagy inducers, namely p53-induced glycolysis and apoptosis regulator (TIGAR) and DNA damage-regulated autophagy modulator (DRAM). In addition, there is another well-recognized pathway related to p62, an important autophagyrelated protein, which combines with the increasingly produced NF-E2-related factor 2 induced by the accumulation of ROS, thus triggering the process of autophagy (131). Besides, several signaling pathways have been discussed in the previous studies, such as the hypoxia inducible factor-BCL2/adenovirus E1B interacting protein 3 (BINP3) pathways, and so on (132) (Figure 2).

In Paneth cells, the ROS-induced autophagy has been reported to facilitate in the treatment of IBD. Previous studies demonstrated that the ROS-mediated antibacterial autophagy (wellknown as "xenophagy") as well as the mitochondrial autophagy (well-known as "mitophagy") in Paneth cells contributed greatly to the attenuation of IBD, thus probably serving as potential strategies for the treatment of IBD $(37,38)$. In addition, since autophagy was essential for maintaining the normal functions of mitochondria, several researches specifically showed that Atg mutations led to the elevation of ROS in several cells, including 
the Paneth cells via the dysfunctional mitochondria $(7,8,37,38)$. Furthermore, it should be noted that the absence of autophagy in Paneth cells largely enhanced the production of ROS and inflammatory cytokines, thus deteriorating the severity of IBD in DSS-induced colitis mice model (133). As a result, ERS may serve as a vital factor in the mechanism by which the abnormal autophagy in Paneth cells contributes to the onset or progression of IBD.

\section{Intestinal Microbiota}

Trillions of bacteria, also called microbiota, colonize in the human intestinal lumen, which help the host to maintain healthy through multiple ways, including assisting the digestion and absorption, educating the immune system, regulating metabolism, and fighting against pathogenic microbes. Microbial imbalance (dysbiosis) contributes to a wide range of diseases, including metabolic syndromes, autism spectrum disorders, IBD, and so on. Among all of the various pathways in maintaining the microbial homeostasis, one of the most important pathways is xenophagy, which refers to a pathogen clearance regulated by autophagy (73). The impeded autophagy induced by bacterial plays a vital role in $C D$, indicating the common defected handling of the microbiota in the gut. For example, studies have shown the lower level of xenophagy led to characteristic alterations in intestinal microbiota in CD patients, including one specific strains of E. coli, namely AIEC, colonizing the intestinal epithelial $(134,135)$.

Burger et al. found that the microbiota could induce basal Paneth cell autophagy by IFN- $\gamma$ so as to maintain intestinal homeostasis (39). However, as we mentioned above, impaired sensing and handling of intracellular microorganisms by IECs is a central part in pathogenesis and progression of IBD. Paneth cells, as one of the main producers of AMPs, were reported to play a key role in sensing and modifying the compositions of microbiota in the intestine (136). For example, the impaired Paneth cells in IBD patients produced lower levels of defensins and lysozymes, which reduced the antimicrobial ability to fight against quantitative bacteria in the intestinal lumen (31). It was reported that the dysfunction of Paneth cell autophagy disturbed the intestinal microbiota, leading to the higher level of AIEC and
Salmonella typhimurium intracellular survival (55). Increasing studies showed that the dysfunctional Paneth cell autophagy which was caused by the mutation of autophagy-related genes could impair the localization of invaded pathogens, the recognition of bacterial, the activation of antimicrobial reactions, as well as the release of various AMPs $(60,137)$. Accumulating evidence suggested that impaired autophagy of Paneth cells not only altered the composition of intestinal bacteria, but also led to improper responses to the changed microbiota $(3,4)$. For example, the impeded xenophagy made intestinal epithelium become hypersensitive to the products of the microbes, thus making the process of bacterial mishandling self-replicating and the onset of IBD $(102,138,139)$. Interestingly, some researchers found that the administration of probiotics alleviated the severity of colitis, which might be a potential effective treatment for IBD $(140,141)$.

\section{AUTOPHAGY-RELATED GENETIC VARIANTS OF PANETH CELLS AND THE THERAPEUTIC ROLE IN IBD}

Autophagy in IECs, especially in Paneth cells, is a highly conventional process which plays a vital role in maintaining intestinal homeostasis by degrading and recycling intracellular materials or organelles $(142,143)$. Increasing studies have shown the importance of autophagy in the pathogenesis and progression of IBD, which has been reported to be closely associated with various genetic mutations. Interestingly, vitamin $\mathrm{D}$ receptor $(V d r)$, autophagy-related 16-like 1 (Atg16l1), and nucleotidebinding oligomerization domaincontaining protein 2 (Nod2), as the best representative IBD-related gene variants, converge to be involved in Paneth cell autophagy $(76,144-147)$. Since autophagy controls the production and quality of lysosome in the granules of Paneth cells, impaired autophagy may probably result in the decreased level of AMPs and dysbiosis, thus contributing to IBD onset (146). In the following contents, those three genetic mutations in GWAS, including Vdr, Atg16l1, and Nod2 as well as other genetic mutations, will be discussed on the connection with IBD in detail (summarized in Table 1).

TABLE 1 | Genetic variants related to autophagy in Paneth cells.

\begin{tabular}{|c|c|c|c|c|}
\hline $\begin{array}{l}\text { Genetic } \\
\text { variants }\end{array}$ & $\begin{array}{l}\text { Types of variants related to } \\
\text { inflammatory bowel disease } \\
\text { (IBD) }\end{array}$ & Mechanisms & $\begin{array}{l}\text { Application } \\
\text { in IBD }\end{array}$ & Reference \\
\hline$V d r$ & Mutation & Sensing the invading bacterial, regulating the expression of Nod 2 & Butyrate & $(152,160-163)$ \\
\hline Nod2 & Mutation & $\begin{array}{l}\text { Producing of } \alpha \text {-defensins, sensing bacterial, forming autophagosome, } \\
\text { regulating inflammatory response }\end{array}$ & - & $(172-176)$ \\
\hline Atg16/1 & Mutation & Sensing bacterial, releasing AMP, forming autophagosome & - & $(102,180,181)$ \\
\hline Xbp1 & Mutation & Regulating ERS & - & $(121)$ \\
\hline Irgm & Mutation & Bacterial killing, vacuolar trafficking and acidification, regulating autophagy & - & $(38,186)$ \\
\hline Atg4 & Deletion & Regulating inflammatory responses & - & $(187)$ \\
\hline Tcf4 & Deletion & Regulating the expression of defensins and cellular differentiation & - & $(188)$ \\
\hline Lrrk2 & Deletion & Regulating the function of autolysosome & - & $(189-192)$ \\
\hline $\operatorname{Atg} 5$ & Deletion & Regulating the function of autolysosome & & (39) \\
\hline
\end{tabular}

Vdr, vitamin D receptor; Nod2, nucleotidebinding oligomerization domaincontaining protein 2; Atg16/1, autophagy-related protein 16-like protein 1; Xbp1, X-box binding protein 1; Irgm, immunity-related GTPase M; Atg4, autophagy-related gene 4; Tcf4, transcription factor; Lrrk2, leucine-rich repeat serine/threonine-protein kinase 2; AMP, adenosine monophosphate; ERS, endoplasmic reticulum stress. 


\section{Vitamin D Receptor}

Vitamin D receptor is one of the most important nuclear receptors which mediates various activities of 1,25-dihydroxyvitamin D3 (vitamin D3), the activated form of vitamin D. When VDR is combined with vitamin D3, retinoid X receptors will heterodimerize with and activate VDR. After binding to vitamin D-response element, the activated VDR will regulate the transcriptional levels of various target genes to maintain the calcium homeostasis in electrolyte and blood pressure (148). Recent studies showed that vitamin D3 might act as a kind of hormone to regulate the innate and adaptive immune responses, suggesting the crucial role of vitamin D3/VDR system in pathology of various diseases (149-151). For example, vitamin $\mathrm{D}$ prevented the invasion of $M$. tuberculosis in lungs, benefited the gut microbiota and improved glucose balance in diabetes. What is more, vitamin D3 pathway could regulate the process of autophagy, such as induction, elongation, engulfment, and maturation, indicating the possible role of VDR in IBD (152).

Low levels of vitamin $\mathrm{D}$ and VDR in expression has been shown in IBD patients (153-155). A North-South gradient in the incidence of $\mathrm{CD}$ indicated that vitamin $\mathrm{D}$ deficiency might contribute to the onset of IBD (155). In addition, patients with polymorphisms of VDR were much more prone to IBD and the same trend was also presented in experimental animal colitis model, where $V d r$ knockout mice developed spontaneous colitis (156-159). Although these findings suggest the close relationship between VDR signaling and IBD, the specific pathway is still unknown. Generally speaking, the target genes of $V d r$, include genes for cathelicidin antimicrobial peptide/interleukin-37 (LL-37) (producing cathelicidin), defensin beta/b (DEFB/b, producing defensins), CLDN2 (encoding claudin 2), and ATG16L1 (related to autophagy), which are mainly responsible against pathogens and maintain the intestinal microbe homeostasis $(160,161)$. For example, it was reported that the pro-inflamma-

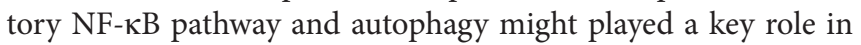
initiating colitis in mice without $V d r(162)$. Accumulating studies also indicated that $V d r$ deletion promoted colitis by activating the NF- $\kappa B$ pathway $(162,163)$. The deficiency of $V d r$ was reported to reduce the level of $\mathrm{I} \kappa \mathrm{B} \alpha$, an endogenous inhibitor of NF- $\kappa \mathrm{B}$ activity, thus promoting the activation of NF- $\mathrm{B}$ pathway, and leading to intestinal inflammatory responses (164). On the other hand, VDR and autophagy are all involved in the onset of IBD (165). Several studies have considered vitamin D as a possible stimulator of autophagy in the infection of M. tuberculosis or HIV infection $(166,167)$.

In addition, some researchers hypothesized that the deficient $V d r$ in IECs reduced the expression of ATG16L1, thus impairing the antimicrobial functions of Paneth cells and increased the bacterial loads in intestinal mucosa and subsequently contributing to the onset of IBD (163). Actually, VDR signaling is a critical factor which regulates nearly $3 \%$ of human genomes, indicating its fundamental roles in the pathogenesis and treatment of IBD (168). It was shown that the deletion of $V d r$ in IECs increased the susceptibility of colitis induced by DSS by altering the composition of intestinal microbiota, such as the decreased amount of Butyrivibrio (163). However, this dysbiosis was reported to be corrected by fecal transplantation (134).
Consequently, there are several possible therapeutic strategies for IBD treatment related to VDR: (1) the administration of bacterial products, such as butyrate which has been shown to increase the expression of VDR and suppress inflammatory responses in a colitis animal model; (2) enhancing intestinal VDR expression which enhances the induction of AMPs to kill pathogenic microbes; and (3) fecal transplantation which helps to rebuild up the intestinal microbial homeostasis and fight against pathogens. However, all of those potential treatments need further explorations.

\section{Nod2}

Nucleotidebinding oligomerization domaincontaining protein 2 (NOD2), a member of the NLR family, was the first susceptibility gene which was closely associated with CD $(30,169)$. As an intracellular sensor of muramyl dipeptide (MDP), much attention has been paid attention to on NOD2 in macrophages (170), while accumulating evidence also showed the vital role of NOD2 in Paneth cells $(30,32,46,47,169,171)$. The first study in German population revealed an obvious decrease of Paneth cell defensins in patients with Nod2 mutations (32). Further analysis in Cleveland Clinic (US) illustrated that this drop was associated with specific Nod2 3020insC frameshift mutation (SNP13) (31).

Several mechanisms may lie in this process, such as the impaired autophagy, decreased bacterial sensing, lower levels of $\alpha$ defensin, and altered immune tolerance by suppressing TLR signals. One of those important mechanisms is the impact of NOD2 on autophagy. In normal cases, once the NOD2 was activated by MDP and pathogens, it could recruit ATG16L1 to sites of bacterial entry and induce autophagosomes in dendritic cells and epithelial cells $(172,173)$. For example, CD patients with Nod2 variants were reported to lack this ability and caused decrease in the function of killing intracellular bacteria, such as AIEC, S. typhimurium, as well as Shigella flexneri $(134,135,172,173)$. A similar distinct decrease in AMPs was also observed in Nod2 knockout mice (138). In addition, the transcellular permeability and bacterial translocation were also increased in Nod2 knockout mice, which might be caused by the reduced production of defensins particularly in Paneth cells (174-176). Apart from the impairment of those functions in the innate immune, studies also reported that the dysfunction of Nod2 might also led to an obvious reduction in the adaptive immunity by decreased bacterial handling in dendritic cells and impaired antigen presentation related to MHC class II on cellular surface (172).

Although its exact functions remain to be unclarified, NOD2 appears to play an important role in IBD through the activation NF- $\kappa \mathrm{B}$ pathway and toll-like receptor pathways. When NOD2 was activated by MDP or bacteria in Paneth cells, it would induce autophagy via the NF-кB pathway (177). On the other hand, the autophagy was reported to promote the delivery of NOD2, thus enhancing the inflammatory responses (172). When facing a great demand of antimicrobial substance, ERS will be induced in Paneth cells, thus increasing the internalization of microbes and contributing to IBD onset (101). Increasing evidence demonstrated that the increased internalization of microbes was further amplified when the cells lack Nod2, which is mainly 
mediated by the ROS and MAPK pathways (47). Specifically speaking, when the epithelia were treated with DNP + E. coli, the level of $I \kappa B$, an activation-related indicator of the NF- $\kappa B$ was decreased, suggesting the vital role of NF- $\kappa \mathrm{B}$ signaling pathway intermediated by ROS (178). In addition, MAPKs-ERK1/2 pathway modifies paracellular and transcellular permeability of IECs to affect the microbial homeostasis in the gut (179).

\section{Atg16/1}

In 2007, the gene of autophagy-related protein 16-like protein 1 (Atg16l1), is one of the most important susceptibility genes, which was reported to be related to autophagy by GWAS (76). This was the first research to illustrate the interaction between autophagy and IBD, indicating that Atg16l1 variants might lead to the dysfunction of Paneth cells. Actually, Atg16l1 deficiency prevents the recruitment and combination of the ATG12-ATG5 complex, consequently impairing the engulfment of pathogens and cellular organelles during the process of autophagic catabolism $(102,180)$. Along with those lines, CD patients with ATG16L1 T300A risk loci exhibited disturbed capture of S. typhimurium in autophagosomes (181).

Recently, some studies provided strong evidence that Paneth cell autophagy imposed pivotal roles in the pathogenesis and progression of IBD $(30,32,46-48,102,169,182)$. In 2008, Cadwell et al. engineered an Atg16l1-deficient mouse and reported the defected Paneth cells which had fewer granules and decreased levels of antimicrobial substance inside (182). They also presented impaired exocytosis pathway of granules through which cellular components, including AMPs and other innate antibiotic peptides were transported to the intestinal lumen. Besides, the abnormal Paneth cell function would increase the production of inflammatory mediators, such as leptin and adiponectin, which were also elevated in IBD patients (183). Similarly, the morphologic changes and granule dysfunctions in Paneth cells was also observed in CD patients with Atg16l1 mutation (102, 183, 184). Furthermore, Cadwell et al. additionally provided interesting data on this issue, showing that Atg16l1 hypomorphic mice together with the infection of MNV CR6 caused abnormal granular secretion in Paneth cells, thus leading to intestinal lesions $(48,137)$. Recently, Matsuzawa-Ishimoto et al. found the mutation of ATG16L1 in intestinal led to the loss of Paneth cells, which was associated with the disturbance of mitochondrial homeostasis (114).

Taken together, those studies indicated that dysfunctional autophagy in Paneth cells induced by Atg16l1 mutation might trigger the dysbiosis in intestine, which made individuals more susceptible to environmental to facilitate the onset of IBD.

\section{Others}

Apart from those three common susceptibility genes for IBD, some other genes involving Paneth cell autophagy have been reported. Among those genes, some genes contributed to the pathogenesis and progression of IBD through genetic mutation. For example, genetic variant in $X b p 1$ was reported to lead to the elevated ERS through the defection in UPR in highly secretory IECs, especially Paneth cells, thus impairing their functions and inducing the onset of $\operatorname{IBD}(98,114)$. In addition, immunity-related GTPase M (Irgm) was also regarded as an IBD-susceptibility gene on chromosome 5q33.1 (185). IRGM is mainly associated with bacterial killing, vacuolar trafficking and acidification, and autophagy induced by microbes, thus maintaining the intestinal homeostasis. In 2008, McCarroll et al. reported a $20 \mathrm{~kb}$ deletion polymorphism upstream from Irgm which could suppress autophagy, thus impairing the ability to clear pathogens and contributing to the onset of IBD (186). In addition, a recent study showed that the location and granule of Paneth cells were greatly affected by IRGM, which was closely associated with the downregulated level of autophagy of Paneth cells (38). The induced Paneth cell autophagy would impair autophagic control of pathogens such as S. typhimurium, thus leading to dysbiosis and the onset of IBD (186).

Besides genetic mutation, several researches revealed that the deletion of some genes also affected Paneth cell autophagy. For example, a recent study focusing on Atg4 genes considered Atg $4 \mathrm{~B}$ as a novel protective protein in regulating inflammatory responses during the pathogenesis of experimental colitis (187). They also found that the level of Atg4B was paralleled with the level of autophagy. Moreover, they found that the expression of Atg4B was obviously decreased in IBD patients, and Paneth cell in mice presented obvious abnormalities after deletion of Atg4B. They demonstrated that Atg $4 b$-null mice model could be used to test new treatments for intestinal diseases associated with autophagy deficiency, including IBD. Those findings indicated the important role of Atg $4 b$ in Paneth cell autophagy and IBD. In addition, TCF was also shown to be associated with antimicrobial dysfunction of Paneth cells and the onset of CD. The deletion of Tcf4 would cause a decreased production of AMPs in Paneth cells and impaired ability to fight against various pathogens by affecting the expression of $\alpha$-defensin and the differentiation of cells (188). Recently, leucine-rich repeat serine/threonine-protein kinase 2 (Lrrk2), a CD-susceptibility gene, was reported to be correlated with xenophagy by affecting the degradation of autophagosome-lysosome (189). Studies demonstrated that the deletion of Lrrk2 resulted in the lower level of lysozyme which might be caused by the impaired Paneth cells autophagy, thus contributing to the onset of IBD (190-192). What is more, a new study revealed the crucial role of the autophagy protein Atg5 in regulating the immune responses and protecting epithelial cells during acute intestinal inflammation. They reported that the specific deletion of Atg5 in Paneth cells contributed to the destruction of the crypts in structure, which was similar to changes in pan-epithelial Atg5deficient mice. Additionally, lack of functional autophagy in Paneth cells led to impaired intestinal permeability. Thus, Atg5 expression in Paneth cells is crucial for tissue protection during acute gastrointestinal infection (39).

\section{CONCLUSION}

In this review, we discussed the roles of Paneth cell autophagy in the pathogenesis and progression of IBD. We mainly focused on the popular mechanisms of Paneth cell autophagy in IBD alleviation, including the regulation of ERS, ROS, and intestinal 
microbiota. In addition, several well-studied genetic variants of Paneth cells and the related treatment roles in IBD were also summarized.

\section{AUTHOR CONTRIBUTIONS}

S-LW, B-ZS and S-BZ retrieved and analyzed concerned literatures. S-LW, B-ZS and S-BZ wrote the manuscript. JF and LG designed the table and figures. C-YM, Z-SL, and YB revised

\section{REFERENCES}

1. Wells JM, Rossi O, Meijerink M, van Baarlen P. Epithelial crosstalk at the microbiota-mucosal interface. Proc Natl Acad Sci U S A (2011) 108:4607-14. doi:10.1073/pnas.1000092107

2. Goto Y, Kiyono H. Epithelial barrier: an interface for the crosscommunication between gut flora and immune system. Immunol Rev (2012) 245:147-63. doi:10.1111/j.1600-065X.2011.01078.x

3. Kaser A, Zeissig S, Blumberg RS. Inflammatory bowel disease. Annu Rev Immunol (2010) 28:573-621. doi:10.1146/annurev-immunol-030409101225

4. Garrett WS, Gordon JI, Glimcher LH. Homeostasis and inflammation in the intestine. Cell (2010) 140:859-70. doi:10.1016/j.cell.2010.01.023

5. Chow J, Lee SM, Shen Y, Khosravi A, Mazmanian SK. Host-bacterial symbiosis in health and disease. Mucosal Immun (2010) 107:243-74. doi:10.1016/ B978-0-12-381300-8.00008-3

6. Antoni L, Nuding S, Wehkamp J, Stange EF. Intestinal barrier in inflammatory bowel disease. World J Gastroenterol (2014) 20:1165-79. doi:10.3748/ wjg.v20.i5.1165

7. Tal MC, Sasai M, Lee HK, Yordy B, Shadel GS, Iwasaki A. Absence of autophagy results in reactive oxygen species-dependent amplification of RLR signaling. Proc Natl Acad Sci U S A (2009) 106:2770-5. doi:10.1073/ pnas.0807694106

8. Stephenson LM, Miller BC, Ng A, Eisenberg J, Zhao Z, Cadwell K, et al. Identification of Atg5-dependent transcriptional changes and increases in mitochondrial mass in Atg5-deficient T lymphocytes. Autophagy (2009) 5:625-35. doi:10.4161/auto.5.5.8133

9. Odenwald MA, Turner JR. The intestinal epithelial barrier: a therapeutic target? Nat Rev Gastroenterol Hepatol (2017) 14:9-21. doi:10.1038/ nrgastro.2016.169

10. Stappenbeck TS, Rioux JD, Mizoguchi A, Saitoh T, Huett A, DarfeuilleMichaud A, et al. Crohn disease: a current perspective on genetics, autophagy and immunity. Autophagy (2011) 7:355-74. doi:10.4161/auto.7.2.13074

11. Ouellette AJ. Paneth cells and innate mucosal immunity. Curr Opin Gastroenterol (2010) 26:547-53. doi:10.1097/MOG.0b013e32833dccde

12. Maslowski KM, Vieira AT, Ng A, Kranich J, Sierro F, Yu D, et al. Regulation of inflammatory responses by gut microbiota and chemoattractant receptor GPR43. Nature (2009) 461:1282-6. doi:10.1038/nature08530

13. Kabat AM, Pott J, Maloy KJ. The mucosal immune system and its regulation by autophagy. Front Immunol (2016) 7:240. doi:10.3389/fimmu.2016. 00240

14. Lee HY, Kim J, Quan W, Lee JC, Kim MS, Kim SH, et al. Autophagy deficiency in myeloid cells increases susceptibility to obesity-induced diabetes and experimental colitis. Autophagy (2016) 12:1390-403. doi:10.1080/15548627. 2016.1184799

15. Negroni A, Colantoni E, Vitali R, Palone F, Pierdomenico M, Costanzo M, et al. NOD2 induces autophagy to control AIEC bacteria infectiveness in intestinal epithelial cells. Inflamm Res (2016) 65:803-13. doi:10.1007/s00011016-0964-8

16. Arrieta MC, Madsen K, Doyle J, Meddings J. Reducing small intestinal permeability attenuates colitis in the IL10 gene-deficient mouse. Gut (2009) 58:41-8. doi:10.1136/gut.2008.150888

17. Turner JR. Intestinal mucosal barrier function in health and disease. Nat Rev Immunol (2009) 9:799-809. doi:10.1038/nri2653

18. Moran AP, Gupta A, Joshi L. Sweet-talk: role of host glycosylation in bacterial pathogenesis of the gastrointestinal tract. Gut (2011) 60:1412-25. doi:10.1136/gut.2010.212704 the manuscript. All the authors agreed to be accountable for the content of the work.

\section{ACKNOWLEDGMENTS}

This work was supported by the National Natural Science Foundation of China (Grant No. 81670473), Research Doctor Fund of Changhai Hospital (B Type) and Three Engineering Training Funds in Shenzhen (Grant No. SYLY201718).

19. Hansson GC. Role of mucus layers in gut infection and inflammation. Curr Opin Microbiol (2012) 15:57-62. doi:10.1016/j.mib.2011.11.002

20. Pearson JP, Brownlee IA. The interaction of large bowel microflora with the colonic mucus barrier. Int J Inflam (2010) 2010:321426. doi:10.4061/ 2010/321426

21. Cederlund A, Gudmundsson GH, Agerberth B. Antimicrobial peptides important in innate immunity. FEBS J (2011) 278:3942-51. doi:10.1111/j. 1742-4658.2011.08302.x

22. Bevins CL, Martin-Porter E, Ganz T. Defensins and innate host defence of the gastrointestinal tract. Gut (1999) 45:911-5. doi:10.1136/gut.45.6.911

23. Brandtzaeg P. Mucosal immunity: induction, dissemination, and effector functions. Scand J Immunol (2009) 70:505-15. doi:10.1111/j.1365-3083. 2009.02319.x

24. Cheng H. Origin, differentiation and renewal of the four main epithelial cell types in the mouse small intestine. IV. Paneth cells. Am J Anat (1974) 141:521-35. doi:10.1002/aja.1001410406

25. McGuckin MA, Lindén SK, Sutton P, Florin TH. Mucin dynamics and enteric pathogens. Nat Rev Microbiol (2011) 9:265-78. doi:10.1038/ nrmicro2538

26. Harrison E, Lal S, McLaughlin JT. Enteroendocrine cells in gastrointestinal pathophysiology. Curr Opin Pharmacol (2013) 13:941-5. doi:10.1016/j. coph.2013.09.012

27. Roda G, Sartini A, Zambon E, Calafiore A, Marocchi M, Caponi A, et al. Intestinal epithelial cells in inflammatory bowel diseases. World J Gastroenterol (2010) 16:4264-71. doi:10.3748/wjg.v16.i34.4264

28. Elphick DA, Mahida YR. Paneth cells: their role in innate immunity and inflammatory disease. Gut (2005) 54:1802-9. doi:10.1136/gut.2005.068601

29. Lala S, Ogura Y, Osborne C, Hor SY, Bromfield A, Davies S, et al. Crohn's disease and the NOD2 gene: a role for paneth cells. Gastroenterology (2003) 125:47-57. doi:10.1016/S0016-5085(03)00661-9

30. Ogura Y, Bonen DK, Inohara N, Nicolae DL, Chen FF, Ramos R, et al. A frameshift mutation in NOD2 associated with susceptibility to Crohn's disease. Nature (2001) 411:603-6. doi:10.1038/35079114

31. Wehkamp J, Salzman NH, Porter E, Nuding S, Weichenthal M, Petras RE, et al. Reduced Paneth cell alpha-defensins in ileal Crohn's disease. Proc Natl Acad Sci U S A (2005) 102:18129-34. doi:10.1073/pnas.0505256102

32. Wehkamp J, Harder J, Weichenthal M, Schwab M, Schäffeler E, Schlee M, et al. NOD2 (CARD15) mutations in Crohn's disease are associated with diminished mucosal alpha-defensin expression. Gut (2004) 53:1658-64. doi:10.1136/gut.2003.032805

33. Vaishnava S, Behrendt CL, Ismail AS, Eckmann L, Hooper LV. Paneth cells directly sense gut commensals and maintain homeostasis at the intestinal host-microbial interface. Proc Natl Acad Sci U S A (2008) 105:20858-63. doi:10.1073/pnas.0808723105

34. Laine VJ, Grass DS, Nevalainen TJ. Resistance of transgenic mice expressing human group II phospholipase A2 to Escherichia coli infection. Infect Immun (2000) 68:87-92. doi:10.1128/IAI.68.1.87-92.2000

35. Kaser A, Martinez-Naves E, Blumberg RS. Endoplasmic reticulum stress: implications for inflammatory bowel disease pathogenesis. Curr Opin Gastroenterol (2010) 26:318-26. doi:10.1097/MOG.0b013e32833a9ff1

36. Bel S, Pendse M, Wang Y, Li Y, Ruhn KA, Hassell B, et al. Paneth cells secrete lysozyme via secretory autophagy during bacterial infection of the intestine. Science (2017) 357:1047-52. doi:10.1126/science.aal4677

37. Billmann-Born S, Lipinski S, Böck J, Till A, Rosenstiel P, Schreiber S. The complex interplay of NOD-like receptors and the autophagy machinery in the pathophysiology of Crohn disease. Eur J Cell Biol (2011) 90:593-602. doi:10.1016/j.ejcb.2010.10.015 
38. Liu B, Gulati AS, Cantillana V, Henry SC, Schmidt EA, Daniell X, et al. Irgm1-deficient mice exhibit Paneth cell abnormalities and increased susceptibility to acute intestinal inflammation. Am J Physiol Gastrointest Liver Physiol (2013) 305:G573-84. doi:10.1152/ajpgi.00071.2013

39. Burger E, Araujo A, López-Yglesias A, Rajala MW, Geng L, Levine B, et al. Loss of Paneth cell autophagy causes acute susceptibility to Toxoplasma gondii-mediated inflammation. Cell Host Microbe (2018) 23(2):177-90.e4. doi:10.1016/j.chom.2018.01.001

40. Burisch J, Munkholm P. Inflammatory bowel disease epidemiology. Curr Opin Gastroenterol (2013) 29:357-62. doi:10.1097/MOG.0b013e32836229fb

41. Molodecky NA, Soon IS, Rabi DM, Ghali WA, Ferris M, Chernoff G, et al. Increasing incidence and prevalence of the inflammatory bowel diseases with time, based on systematic review. Gastroenterology (2012) 142:46-54. e42. doi:10.1053/j.gastro.2011.10.001

42. Wallace KL, Zheng LB, Kanazawa Y, Shih DQ. Immunopathology of inflammatory bowel disease. World J Gastroenterol (2014) 20:6-21. doi:10.3748/ wjg.v20.i1.6

43. Breslin NP, Todd A, Kilgallen C, O'Morain C. Monozygotic twins with Crohn's disease and ulcerative colitis: a unique case report. Gut (1997) 41:557-60. doi:10.1136/gut.41.4.557

44. de Lange KM, Barrett JC. Understanding inflammatory bowel disease via immunogenetics. J Autoimmun (2015) 64:91-100. doi:10.1016/j.jaut.2015. 07.013

45. Liu JZ, van Sommeren S, Huang H, Ng SC, Alberts R, Takahashi A, et al. Association analyses identify 38 susceptibility loci for inflammatory bowel disease and highlight shared genetic risk across populations. Nat Genet (2015) 47:979-86. doi:10.1038/ng.3359

46. Jostins L, Ripke S, Weersma RK, Duerr RH, McGovern DP, Hui KY, et al. Host-microbe interactions have shaped the genetic architecture of inflammatory bowel disease. Nature (2012) 491:119-24. doi:10.1038/nature11582

47. Khor B, Gardet A, Xavier RJ. Genetics and pathogenesis of inflammatory bowel disease. Nature (2011) 474:307-17. doi:10.1038/nature10209

48. Cadwell K, Patel KK, Maloney NS, Liu TC, Ng AC, Storer CE, et al. Virus-plus-susceptibility gene interaction determines Crohn's disease gene Atg16L1 phenotypes in intestine. Cell (2010) 141:1135-45. doi:10.1016/j. cell.2010.05.009

49. Birrenbach T, Bocker U. Inflammatory bowel disease and smoking: a review of epidemiology, pathophysiology, and therapeutic implications. Inflamm Bowel Dis (2004) 10:848-59. doi:10.1097/00054725-200411000-00019

50. Ananthakrishnan AN, McGinley EL, Binion DG, Saeian K. Ambient air pollution correlates with hospitalizations for inflammatory bowel disease: an ecologic analysis. Inflamm Bowel Dis (2011) 17:1138-45. doi:10.1002/ ibd. 21455

51. Kaplan GG, Hubbard J, Korzenik J, Sands BE, Panaccione R, Ghosh S, et al. The inflammatory bowel diseases and ambient air pollution: a novel association. Am J Gastroenterol (2010) 105:2412-9. doi:10.1038/ajg.2010.252

52. Larsson JM, Karlsson H, Crespo JG, Johansson ME, Eklund L, Sjövall H, et al. Altered O-glycosylation profile of MUC2 mucin occurs in active ulcerative colitis and is associated with increased inflammation. Inflamm Bowel Dis (2011) 17:2299-307. doi:10.1002/ibd.21625

53. Giles EM, Sanders TJ, McCarthy NE, Lung J, Pathak M, MacDonald TT, et al. Regulation of human intestinal T-cell responses by type 1 interferon-STAT1 signaling is disrupted in inflammatory bowel disease. Mucosal Immunol (2017) 10:184-93. doi:10.1038/mi.2016.44

54. Tosiek MJ, Fiette L, El Daker S, Eberl G, Freitas AA. IL-15-dependent balance between Foxp3 and RORgammat expression impacts inflammatory bowel disease. Nat Commun (2016) 7:10888. doi:10.1038/ncomms10888

55. Kostic AD, Xavier RJ, Gevers D. The microbiome in inflammatory bowel disease: current status and the future ahead. Gastroenterology (2014) 146:1489-99. doi:10.1053/j.gastro.2014.02.009

56. Martinez-Medina M, Aldeguer X, Lopez-Siles M, González-Huix F, LópezOliu C, Dahbi G, et al. Molecular diversity of Escherichia coli in the human gut: new ecological evidence supporting the role of adherent-invasive E. coli (AIEC) in Crohn's disease. Inflamm Bowel Dis (2009) 15:872-82. doi:10.1002/ ibd. 20860

57. Hviid A, Svanstrom H, Frisch M. Antibiotic use and inflammatory bowel diseases in childhood. Gut (2011) 60:49-54. doi:10.1136/gut.2010.219683

58. Pavel M, Rubinsztein DC. Mammalian autophagy and the plasma membrane. FEBS J (2017) 284:672-9. doi:10.1111/febs.13931
59. Rakoff-Nahoum S, Paglino J, Eslami-Varzaneh F, Edberg S, Medzhitov R. Recognition of commensal microflora by toll-like receptors is required for intestinal homeostasis. Cell (2004) 118(2):229-41. doi:10.1016/j.cell.2004.07.002

60. Kernbauer E, Cadwell K. Autophagy, viruses, and intestinal immunity. Curr Opin Gastroenterol (2014) 30:539-46. doi:10.1097/MOG.0000000000000121

61. Li Y, Yu G, Yuan S, Tan C, Xie J, Ding Y, et al. 14,15-Epoxyeicosatrienoic acid suppresses cigarette smoke condensate-induced inflammation in lung epithelial cells by inhibiting autophagy. Am J Physiol Lung Cell Mol Physiol (2016) 311:L970-80. doi:10.1152/ajplung.00161.2016

62. Huber LA, Teis D. Lysosomal signaling in control of degradation pathways. Curr Opin Cell Biol (2016) 39:8-14. doi:10.1016/j.ceb.2016.01.006

63. Xilouri M, Stefanis L. Chaperone mediated autophagy in aging: starve to prosper. Ageing Res Rev (2016) 32:13-21. doi:10.1016/j.arr.2016.07.001

64. Deretic V. Autophagy in leukocytes and other cells: mechanisms, subsystem organization, selectivity, and links to innate immunity. J Leukoc Biol (2016) 100:969-78. doi:10.1189/jlb.4MR0216-079R

65. Shao BZ, Han BZ, Zeng YX, Su DF, Liu C. The roles of macrophage autophagy in atherosclerosis. Acta Pharmacol Sin (2016) 37:150-6. doi:10.1038/ aps. 2015.87

66. Sica V, Galluzzi L, Bravo-San Pedro JM, Izzo V, Maiuri MC, Kroemer G. Organelle-specific initiation of autophagy. Mol Cell (2015) 59:522-39. doi:10.1016/j.molcel.2015.07.021

67. Brest P, Corcelle EA, Cesaro A, Chargui A, Belaïd A, Klionsky DJ, et al. Autophagy and Crohn's disease: at the crossroads of infection, inflammation, immunity, and cancer. Curr Mol Med (2010) 10:486-502. doi:10.2174/ 156652410791608252

68. Mihaylova MM, Shaw RJ. The AMPK signalling pathway coordinates cell growth, autophagy and metabolism. Nat Cell Biol (2011) 13:1016-23. doi: $10.1038 /$ ncb2329

69. Muzes G, Tulassay Z, Sipos F. Interplay of autophagy and innate immunity in Crohn's disease: a key immunobiologic feature. World J Gastroenterol (2013) 19:4447-54. doi:10.3748/wjg.v19.i28.4447

70. Salio M, Puleston DJ, Mathan TS, Shepherd D, Stranks AJ, Adamopoulou E, et al. Essential role for autophagy during invariant NKT cell development. Proc Natl Acad Sci U S A (2014) 111:E5678-87. doi:10.1073/pnas.1413935112

71. Martinez J, Cunha LD, Park S, Yang M, Lu Q, Orchard R, et al. Corrigendum: noncanonical autophagy inhibits the autoinflammatory, lupus-like response to dying cells. Nature (2016) 539:124. doi:10.1038/nature19837

72. Cho JH, Brant SR. Recent insights into the genetics of inflammatory bowel disease. Gastroenterology (2011) 140:1704-U21. doi:10.1053/j. gastro.2011.02.046

73. Gardet A, Xavier RJ. Common alleles that influence autophagy and the risk for inflammatory bowel disease. Curr Opin Immunol (2012) 24:522-9. doi:10.1016/j.coi.2012.08.001

74. Gutierrez MG, Master SS, Singh SB, Taylor GA, Colombo MI, Deretic V. Autophagy is a defense mechanism inhibiting BCG and Mycobacterium tuberculosis survival in infected macrophages. Cell (2004) 119:753-66. doi:10.1016/j.cell.2004.11.038

75. Nakagawa I, Amano A, Mizushima N, Yamamoto A, Yamaguchi H, Kamimoto T, et al. Autophagy defends cells against invading group A Streptococcus. Science (2004) 306:1037-40. doi:10.1126/science.1103966

76. Hampe J, Franke A, Rosenstiel P, Till A, Teuber M, Huse K, et al. A genome-wide association scan of nonsynonymous SNPs identifies a susceptibility variant for Crohn disease in ATG16L1. Nat Genet (2007) 39:207-11. doi:10.1038/ng1954

77. Ohsumi Y. Molecular dissection of autophagy: two ubiquitin-like systems. Nat Rev Mol Cell Biol (2001) 2:211-6. doi:10.1038/35056522

78. Randall-Demllo S, Chieppa M, Eri R. Intestinal epithelium and autophagy: partners in gut homeostasis. Front Immunol (2013) 4:301. doi:10.3389/ fimmu.2013.00301

79. van de Veerdonk FL, Dinarello CA. Deficient autophagy unravels the ROS paradox in chronic granulomatous disease. Autophagy (2014) 10:1141-2. doi:10.4161/auto. 28638

80. Zhang Q, Kang R, Zeh HJ III, Lotze MT, Tang D. DAMPs and autophagy: cellular adaptation to injury and unscheduled cell death. Autophagy (2013) 9:451-8. doi:10.4161/auto.23691

81. Mizushima N, Levine B, Cuervo AM, Klionsky DJ. Autophagy fights disease through cellular self-digestion. Nature (2008) 451:1069-75. doi:10.1038/ nature06639 
82. Maeda S, Hikiba Y, Shibata W, Ohmae T, Yanai A, Ogura K, et al. Essential roles of high-mobility group box 1 in the development of murine colitis and colitis-associated cancer. Biochem Biophys Res Commun (2007) 360:394-400. doi:10.1016/j.bbrc.2007.06.065

83. Beltran B, Nos P, Dasi F, Iborra M, Bastida G, Martínez M, et al. Mitochondrial dysfunction, persistent oxidative damage, and catalase inhibition in immune cells of naive and treated Crohn's disease. Inflamm Bowel Dis (2010) 16:76-86. doi:10.1002/ibd.21027

84. Meuwis MA, Vernier-Massouille G, Grimaud JC, Bouhnik Y, Laharie D, Piver E, et al. Serum calprotectin as a biomarker for Crohn's disease. J Crohns Colitis (2013) 7:e678-83. doi:10.1016/j.crohns.2013.06.008

85. Li W, Zhu S, Li J, Assa A, Jundoria A, Xu J, et al. EGCG stimulates autophagy and reduces cytoplasmic HMGB1 levels in endotoxin-stimulated macrophages. Biochem Pharmacol (2011) 81:1152-63. doi:10.1016/j.bcp. 2011.02.015

86. Thorburn J, Horita H, Redzic J, Hansen K, Frankel AE, Thorburn A. Autophagy regulates selective HMGB1 release in tumor cells that are destined to die. Cell Death Differ (2009) 16:175-83. doi:10.1038/cdd.2008.143

87. Dupont N, Jiang S, Pilli M, Ornatowski W, Bhattacharya D, Deretic V. Autophagy-based unconventional secretory pathway for extracellular delivery of IL-1beta. EMBO J (2011) 30:4701-11. doi:10.1038/emboj.2011.398

88. Stappenbeck TS. Paneth cell development, differentiation, and function: new molecular cues. Gastroenterology (2009) 137:30-3. doi:10.1053/j. gastro.2009.05.013

89. Salzman NH, Ghosh D, Huttner KM, Paterson Y, Bevins CL. Protection against enteric salmonellosis in transgenic mice expressing a human intestinal defensin. Nature (2003) 422:522-6. doi:10.1038/nature01520

90. Salzman NH, Hung K, Haribhai D, Chu H, Karlsson-Sjöberg J, Amir E, et al. Enteric defensins are essential regulators of intestinal microbial ecology. Nat Immunol (2010) 11:76-83. doi:10.1038/ni.1825

91. Baxt LA, Xavier RJ. Role of autophagy in the maintenance of intestinal homeostasis. Gastroenterology (2015) 149:553-62. doi:10.1053/j.gastro.2015.06.046

92. Bevins CL, Salzman NH. Paneth cells, antimicrobial peptides and maintenance of intestinal homeostasis. Nat Rev Microbiol (2011) 9:356-68. doi:10.1038/nrmicro2546

93. Porter EM, Bevins CL, Ghosh D, Ganz T. The multifaceted Paneth cell. Cell Mol Life Sci (2002) 59:156-70. doi:10.1007/s00018-002-8412-z

94. Adolph TE, Tomczak MF, Niederreiter L, Ko HJ, Böck J, Martinez-Naves E, et al. Paneth cells as a site of origin for intestinal inflammation. Nature (2013) 503:272. doi:10.1038/nature12599

95. Ke P, Shao BZ, Xu ZQ, Chen XW, Liu C. Intestinal autophagy and its pharmacological control in inflammatory bowel disease. Front Immunol (2017) 7:695. doi:10.3389/fimmu.2016.00695

96. Wehkamp J, Schmid M, Fellermann K, Stange EF. Defensin deficiency, intestinal microbes, and the clinical phenotypes of Crohn's disease. J Leukoc Biol (2005) 77:460-5. doi:10.1189/jlb.0904543

97. Dörfel D, Appel S, Grünebach F, Weck MM, Müller MR, Heine A, et al. Processing and presentation of HLA class I and II epitopes by dendritic cells after transfection with in vitro-transcribed MUC1 RNA. Blood (2005) 105:3199-205. doi:10.1182/blood-2004-09-3556

98. Kaser A, Lee AH, Franke A, Glickman JN, Zeissig S, Tilg H, et al. XBP1 links ER stress to intestinal inflammation and confers genetic risk for human inflammatory bowel disease. Cell (2008) 134:743-56. doi:10.1016/j. cell.2008.07.021

99. Ma X, Dai Z, Sun K, Zhang Y, Chen J, Yang Y, et al. Intestinal epithelial cell endoplasmic reticulum stress and inflammatory bowel disease pathogenesis: an update review. Front Immunol (2017) 8:1271. doi:10.3389/ fimmu.2017.01271

100. Kaser A, Adolph TE, Blumberg RS. The unfolded protein response and gastrointestinal disease. Semin Immunopathol (2013) 35:307-19. doi:10.1007/ s00281-013-0377-5

101. McGuckin MA, Eri RD, Das I, Lourie R, Florin TH. ER stress and the unfolded protein response in intestinal inflammation. Am J Physiol Gastrointest Liver Physiol (2010) 298:G820-32. doi:10.1152/ajpgi.00063.2010

102. Cadwell K, Liu JY, Brown SL, Miyoshi H, Loh J, Lennerz JK, et al. A key role for autophagy and the autophagy gene Atg16l1 in mouse and human intestinal Paneth cells. Nature (2008) 456:259-63. doi:10.1038/nature07416

103. Oyadomari S, Mori M. Roles of CHOP/GADD153 in endoplasmic reticulum stress. Cell Death Differ (2004) 11:381-9. doi:10.1038/sj.cdd.4401373
104. Sano R, Reed JC. ER stress-induced cell death mechanisms. Biochim Biophys Acta (2013) 1833:3460-70. doi:10.1016/j.bbamcr.2013.06.028

105. Urano F, Wang X, Bertolotti A, Zhang Y, Chung P, Harding HP, et al. Coupling of stress in the ER to activation of JNK protein kinases by transmembrane protein kinase IRE1. Science (2000) 287:664-6. doi:10.1126/ science.287.5453.664

106. Kaneko M, Niinuma Y, Nomura Y. Activation signal of nuclear factor-kappa $B$ in response to endoplasmic reticulum stress is transduced via IRE1 and tumor necrosis factor receptor-associated factor 2. Biol Pharm Bull (2003) 26:931-5. doi:10.1248/bpb.26.931

107. McGovern DP, Gardet A, Törkvist L, Goyette P, Essers J, Taylor KD, et al. Genome-wide association identifies multiple ulcerative colitis susceptibility loci. Nat Genet (2010) 42:332-7. doi:10.1038/ng.549

108. Ogata M, Hino S, Saito A, Morikawa K, Kondo S, Kanemoto S, et al. Autophagy is activated for cell survival after endoplasmic reticulum stress. Mol Cell Biol (2006) 26:9220-31. doi:10.1128/MCB.01453-06

109. Hart LS, Cunningham JT, Datta T, Dey S, Tameire F, Lehman SL, et al. ER stress-mediated autophagy promotes Myc-dependent transformation and tumor growth. J Clin Invest (2012) 122:4621-34. doi:10.1172/JCI62973

110. Li J, Ni M, Lee B, Barron E, Hinton DR, Lee AS. The unfolded protein response regulator $\mathrm{GRP} 78 / \mathrm{BiP}$ is required for endoplasmic reticulum integrity and stress-induced autophagy in mammalian cells. Cell Death Differ (2008) 15:1460-71. doi:10.1038/cdd.2008.81

111. Heazlewood CK, Cook MC, Eri R, Price GR, Tauro SB, Taupin D, et al. Aberrant mucin assembly in mice causes endoplasmic reticulum stress and spontaneous inflammation resembling ulcerative colitis. PLoS Med (2008) 5:e54. doi:10.1371/journal.pmed.0050054

112. Fritz T, Niederreiter L, Adolph T, Blumberg RS, Kaser A. Crohn's disease: NOD2, autophagy and ER stress converge. Gut (2011) 60:1580-8. doi:10.1136/gut.2009.206466

113. Kaser A, Blumberg RS. ATG16L1 Crohn's disease risk stresses the endoplasmic reticulum of Paneth cells. Gut (2014) 63:1038-9. doi:10.1136/ gutjnl-2013-306103

114. Matsuzawa-Ishimoto Y, Shono Y, GomezLE, Hubbard-Lucey VM,Cammer M, Neil J, et al. Autophagy protein ATG16L1 prevents necroptosis in the intestinal epithelium. J Exp Med (2017) 214:3687-705. doi:10.1084/jem.20170558

115. Bel S, Hooper LV. Secretory autophagy of lysozyme in Paneth cells. Autophagy (2018) 8:1-3. doi:10.1080/15548627.2018.1430462

116. Delorme-Axford E, Klionsky DJ. Secretory autophagy holds the key to lysozyme secretion during bacterial infection of the intestine. Autophagy (2018) 29:1-3. doi:10.1080/15548627.2017.1401425

117. Biczo G, Vegh ET, Shalbueva N, Mareninova OA, Elperin J, Lotshaw E, et al. Mitochondrial dysfunction, through impaired autophagy, leads to endoplasmic reticulum stress, deregulated lipid metabolism, and pancreatitis in animal models. Gastroenterology (2018) 154(3):689-703. doi:10.1053/j. gastro.2017.10.012

118. El-Khider F, McDonald C. Links of autophagy dysfunction to inflammatory bowel disease onset. Dig Dis (2016) 34:27-34. doi:10.1159/000442921

119. Kokten T, Gibot S, Lepage P, D’Alessio S, Hablot J, Ndiaye NC, et al. TREM-1 inhibition restores impaired autophagy activity and reduces colitis in mice. J Crohns Colitis (2018) 12(2):230-44. doi:10.1093/ecco-jcc/jjx129

120. Tschurtschenthaler M, Adolph TE, Ashcroft JW, Niederreiter L, Bharti R, Saveljeva S, et al. Defective ATG16L1-mediated removal of IRE1alpha drives Crohn's disease-like ileitis. J Exp Med (2017) 214:401-22. doi:10.1084/ jem.20160791

121. Diebold L, Chandel NS. Mitochondrial ROS regulation of proliferating cells. Free Radic Biol Med (2016) 100:86-93. doi:10.1016/j. freeradbiomed.2016.04.198

122. Keshavarzian A, Sedghi S, Kanofsky J, List T, Robinson C, Ibrahim C, et al. Excessive production of reactive oxygen metabolites by inflamed colon: analysis by chemiluminescence probe. Gastroenterology (1992) 103:177-85. doi:10.1016/0016-5085(92)91111-G

123. Clark E, Hoare C, Tanianis-Hughes J, Carlson GL, Warhurst G. Interferon gamma induces translocation of commensal Escherichia coli across gut epithelial cells via a lipid raft-mediated process. Gastroenterology (2005) 128:1258-67. doi:10.1053/j.gastro.2005.01.046

124. Ma TY, Hollander D, Freeman D, Nguyen T, Krugliak P. Oxygen free radical injury of IEC-18 small intestinal epithelial cell monolayers. Gastroenterology (1991) 100:1533-43. doi:10.1016/0016-5085(91)90650-A 
125. Wang A, Keita ÅV, Phan V, McKay CM, Schoultz I, Lee J, et al. Targeting mitochondria-derived reactive oxygen species to reduce epithelial barrier dysfunction and colitis. Am J Pathol (2014) 184:2516-27. doi:10.1016/j. ajpath.2014.05.019

126. Huang Y, Zhou J, Luo S, Wang Y, He J, Luo P, et al. Identification of a fluorescent small-molecule enhancer for therapeutic autophagy in colorectal cancer by targeting mitochondrial protein translocase TIM44. Gut (2018) 67:307-19. doi:10.1136/gutjnl-2016-311909

127. Diakopoulos KN, Lesina M, Wörmann S, Song L, Aichler M, Schild L, et al. Impaired autophagy induces chronic atrophic pancreatitis in mice via sexand nutrition-dependent processes. Gastroenterology (2015) 148:626-38.e17. doi:10.1053/j.gastro.2014.12.003

128. Ma X, Liu H, Foyil SR, Godar RJ, Weinheimer CJ, Hill JA, et al. Impaired autophagosome clearance contributes to cardiomyocyte death in ischemia/reperfusion injury. Circulation (2012) 125:3170-81. doi:10.1161/ CIRCULATIONAHA.111.041814

129. Zhang C, Li P, Zhang S, Lei R, Li B, Wu X, et al. Oxidative stress-elicited autophagosome accumulation contributes to human neuroblastoma SH-SY5Y cell death induced by PBDE-47. Environ Toxicol Pharmacol (2017) 56:322-8. doi:10.1016/j.etap.2017.10.007

130. Rodrigo R, Fernández-Gajardo R, Gutiérrez R, Matamala JM, Carrasco R, Miranda-Merchak A, et al. Oxidative stress and pathophysiology of ischemic stroke: novel therapeutic opportunities. CNS Neurol Disord Drug Targets (2013) 12:698-714. doi:10.2174/1871527311312050015

131. Cheung EC, Ludwig RL, Vousden KH. Mitochondrial localization of TIGAR under hypoxia stimulates HK2 and lowers ROS and cell death. Proc Natl Acad Sci U S A (2012) 109:20491-6. doi:10.1073/pnas.1206530109

132. Mahalingaiah PK, Singh KP. Chronic oxidative stress increases growth and tumorigenic potential of MCF-7 breast cancer cells. PLoS One (2014) 9:e87371. doi:10.1371/journal.pone.0087371

133. Zhang H, Zheng L, Chen J, Fukata M, Ichikawa R, Shih DQ, et al. The protection role of Atg1611 in CD11c(+)dendritic cells in murine colitis. Immunobiology (2017) 222:831-41. doi:10.1016/j.imbio.2017.03.002

134. Darfeuille-Michaud A, Boudeau J, Bulois P, Neut C, Glasser AL, Barnich N, et al. High prevalence of adherent-invasive Escherichia coli associated with ileal mucosa in Crohn's disease. Gastroenterology (2004) 127:412-21. doi:10.1053/j.gastro.2004.04.061

135. Darfeuille-Michaud A, Neut C, Barnich N, Lederman E, Di Martino P, Desreumaux P, et al. Presence of adherent Escherichia coli strains in ileal mucosa of patients with Crohn's disease. Gastroenterology (1998) 115: 1405-13. doi:10.1016/S0016-5085(98)70019-8

136. Sankaran-Walters S, Hart R, Dills C. Guardians of the gut: enteric defensins. Front Microbiol (2017) 8:647. doi:10.3389/fmicb.2017.00647

137. Lapaquette P, Bringer MA, Darfeuille-Michaud A. Defects in autophagy favour adherent-invasive Escherichia coli persistence within macrophages leading to increased pro-inflammatory response. Cell Microbiol (2012) 14:791-807. doi:10.1111/j.1462-5822.2012.01768.x

138. Kobayashi KS, Chamaillard M, Ogura Y, Henegariu O, Inohara N, Nuñez G, et al. Nod2-dependent regulation of innate and adaptive immunity in the intestinal tract. Science (2005) 307:731-4. doi:10.1126/science.1104911

139. Kaser A, Blumberg RS. Endoplasmic reticulum stress in the intestinal epithelium and inflammatory bowel disease. Semin Immunol (2009) 21:156-63. doi:10.1016/j.smim.2009.01.001

140. Rutgeerts P, Van Assche G, Vermeire S, D’Haens G, Baert F, Noman M, et al. Ornidazole for prophylaxis of postoperative Crohn's disease recurrence: a randomized, double-blind, placebo-controlled trial. Gastroenterology (2005) 128:856-61. doi:10.1053/j.gastro.2005.01.010

141. Sartor RB. Therapeutic manipulation of the enteric microflora in inflammatory bowel diseases: antibiotics, probiotics, and prebiotics. Gastroenterology (2004) 126:1620-33. doi:10.1053/j.gastro.2004.03.024

142. Levine B, Mizushima N, Virgin HW. Autophagy in immunity and inflammation. Nature (2011) 469:323-35. doi:10.1038/nature09782

143. Klionsky DJ, Emr SD. Autophagy as a regulated pathway of cellular degradation. Science (2000) 290:1717-21. doi:10.1126/science.290. 5497.1717

144. Barrett JC, Hansoul S, Nicolae DL, Cho JH, Duerr RH, Rioux JD, et al. Genome-wide association defines more than 30 distinct susceptibility loci for Crohn's disease. Nat Genet (2008) 40:955-62. doi:10.1038/ng.175
145. Cadwell K. Crohn's disease susceptibility gene interactions, a NOD to the newcomer ATG16L1. Gastroenterology (2010) 139:1448-50. doi:10.1053/j. gastro.2010.09.023

146. Deretic V, Master S, Singh S. Autophagy gives a nod and a wink to the inflammasome and Paneth cells in Crohn's disease. Dev Cell (2008) 15:641-2. doi:10.1016/j.devcel.2008.10.009

147. Thachil E, Hugot JP, Arbeille B, Paris R, Grodet A, Peuchmaur M, et al. Abnormal activation of autophagy-induced crinophagy in Paneth cells from patients with Crohn's disease. Gastroenterology (2012) 142:1097-9.e4. doi:10.1016/S0016-5085(12)62632-8

148. Demay MB. Mechanism of vitamin D receptor action. Ann N Y Acad Sci (2006) 1068:204-13. doi:10.1196/annals.1346.026

149. Tsoukas CD, Provvedini DM, Manolagas SC. 1,25-dihydroxyvitamin D3: a novel immunoregulatory hormone. Science (1984) 224:1438-40. doi:10.1126/ science. 6427926

150. Adams JS, Hewison M. Unexpected actions of vitamin D: new perspectives on the regulation of innate and adaptive immunity. Nat Clin Pract Endocrinol Metab (2008) 4:80-90. doi:10.1038/ncpendmet0716

151. Barbalho SM, Goulart RA, Gasparini RG. Associations between inflammatory bowel diseases and vitamin D. Crit Rev Food Sci Nutr (2017) 13:1-10. doi:10.1080/10408398.2017.1406333

152. Stio M, Martinesi M, Bruni S, Treves C, d'Albasio G, Bagnoli S, et al. Interaction among vitamin $\mathrm{D}(3)$ analogue KH 1060, TNF-alpha, and vitamin $\mathrm{D}$ receptor protein in peripheral blood mononuclear cells of inflammatory bowel disease patients. Int Immunopharmacol (2006) 6:1083-92. doi:10.1016/j.intimp.2006.01.018

153. Abreu MT, Kantorovich V, Vasiliauskas EA, Gruntmanis U, Matuk R, Daigle $\mathrm{K}$, et al. Measurement of vitamin D levels in inflammatory bowel disease patients reveals a subset of Crohn's disease patients with elevated 1,25-dihydroxyvitamin D and low bone mineral density. Gut (2004) 53:1129-36. doi:10.1136/gut.2003.036657

154. Sentongo TA, Semaeo EJ, Stettler N, Piccoli DA, Stallings VA, Zemel BS. Vitamin D status in children, adolescents, and young adults with Crohn disease. Am J Clin Nutr (2002) 76:1077-81. doi:10.1093/ajcn/76. 5.1077

155. Lim WC, Hanauer SB, Li YC. Mechanisms of disease: vitamin D and inflammatory bowel disease. Nat Clin Pract Gastroenterol Hepatol (2005) 2:308-15. doi:10.1038/ncpgasthep0215

156. Eloranta JJ, Wenger C, Mwinyi J, Hiller C, Gubler C, Vavricka SR, et al. Association of a common vitamin D-binding protein polymorphism with inflammatory bowel disease. Pharmacogenet Genomics (2011) 21:559-64. doi:10.1097/FPC.0b013e328348f70c

157. Hughes DJ, McManus R, Neary P, O'morain C, O’sullivan M. Common variation in the vitamin $\mathrm{D}$ receptor gene and risk of inflammatory bowel disease in an Irish case-control study. Eur J Gastroenterol Hepatol (2011) 23:807-12. doi:10.1097/MEG.0b013e328349283e

158. Ananthakrishnan AN, Khalili H, Higuchi LM, Bao Y, Korzenik JR, Giovannucci EL, et al. Higher predicted vitamin D status is associated with reduced risk of Crohn's disease. Gastroenterology (2012) 142:482-9. doi:10.1053/j.gastro.2011.11.040

159. Froicu M, Zhu Y, Cantorna MT. Vitamin D receptor is required to control gastrointestinal immunity in IL-10 knockout mice. Immunology (2006) 117:310-8. doi:10.1111/j.1365-2567.2005.02290.x

160. Gombart AF, Borregaard N, Koeffler HP. Human cathelicidin antimicrobial peptide (CAMP) gene is a direct target of the vitamin $\mathrm{D}$ receptor and is strongly up-regulated in myeloid cells by 1,25-dihydroxyvitamin D3. FASEB $J$ (2005) 19:1067-77. doi:10.1096/ff.04-3284com

161. Wang TT, Nestel FP, Bourdeau V, Nagai Y, Wang Q, Liao J, et al. Cutting edge: 1,25-dihydroxyvitamin D3 is a direct inducer of antimicrobial peptide gene expression. J Immunol (2004) 173:2909-12. doi:10.4049/ jimmunol.173.10.6490-c

162. Wu S, Xia Y, Liu X, Sun J. Vitamin D receptor deletion leads to reduced level of IkappaBalpha protein through protein translation, protein-protein interaction, and post-translational modification. Int J Biochem Cell Biol (2010) 42:329-36. doi:10.1016/j.biocel.2009.11.012

163. Wu S, Zhang YG, Lu R, Xia Y, Zhou D, Petrof EO, et al. Intestinal epithelial vitamin D receptor deletion leads to defective autophagy in colitis. Gut (2015) 64:1082-94. doi:10.1136/gutjnl-2014-307436 
164. Sun J.VDR/vitamin D receptor regulates autophagic activity through ATG16L1. Autophagy (2016) 12:1057-8. doi:10.1080/15548627.2015.1072670

165. Verway M, Behr MA, White JH. Vitamin D, NOD2, autophagy and Crohn's disease. Expert Rev Clin Immunol (2010) 6:505-8. doi:10.1586/eci.10.31

166. Yuk JM, Shin DM, Lee HM, Yang CS, Jin HS, Kim KK, et al. Vitamin D3 induces autophagy in human monocytes/macrophages via cathelicidin. Cell Host Microbe (2009) 6:231-43. doi:10.1016/j.chom.2009.08.004

167. Campbell GR, Spector SA. Vitamin D inhibits human immunodeficiency virus type 1 and Mycobacterium tuberculosis infection in macrophages through the induction of autophagy. PLoS Pathog (2012) 8:e1002689. doi:10.1371/journal.ppat.1002689

168. Bouillon R, Carmeliet G, Verlinden L, van Etten E, Verstuyf A, Luderer HF, et al. Vitamin D and human health: lessons from vitamin D receptor null mice. Endocr Rev (2008) 29:726-76. doi:10.1210/er.2008-0004

169. Hugot JP, Chamaillard M, Zouali H, Lesage S, Cézard JP, Belaiche J, et al. Association of NOD2 leucine-rich repeat variants with susceptibility to Crohn's disease. Nature (2001) 411:599-603. doi:10.1038/35079107

170. Netea MG, Ferwerda G, de Jong DJ, Werts C, Boneca IG, Jéhanno M, et al. The frameshift mutation in Nod2 results in unresponsiveness not only to Nod2- but also Nod1-activating peptidoglycan agonists. J Biol Chem (2005) 280:35859-67. doi:10.1074/jbc.M504924200

171. Biswas A, Liu YJ, Hao L, Mizoguchi A, Salzman NH, Bevins CL, et al. Induction and rescue of Nod2-dependent Th1-driven granulomatous inflammation of the ileum. Proc Natl Acad Sci U S A (2010) 107:14739-44. doi:10.1073/pnas.1003363107

172. Cooney R, Baker J, Brain O, Danis B, Pichulik T, Allan P, et al. NOD2 stimulation induces autophagy in dendritic cells influencing bacterial handling and antigen presentation. Nat Med (2010) 16:90-7. doi:10.1038/nm.2069

173. Travassos LH, Carneiro LA, Ramjeet M, Hussey S, Kim YG, Magalhães JG, et al. Nod1 and Nod2 direct autophagy by recruiting ATG16L1 to the plasma membrane at the site of bacterial entry. Nat Immunol (2010) 11:55-U67. doi:10.1038/ni.1823

174. Barreau F, Madre C, Meinzer U, Berrebi D, Dussaillant M, Merlin F, et al. Nod 2 regulates the host response towards microflora by modulating $\mathrm{T}$ cell function and epithelial permeability in mouse Peyer's patches. Gut (2010) 59:207-17. doi:10.1136/gut.2008.171546

175. Natividad JM, Petit V, Huang X, de Palma G, Jury J, Sanz Y, et al. Commensal and probiotic bacteria influence intestinal barrier function and susceptibility to colitis in Nod1-/-; Nod2-/- mice. Inflamm Bowel Dis (2012) 18:1434-46. doi:10.1002/ibd.22848

176. Wirtz S, Neurath MF. Mouse models of inflammatory bowel disease. $A d v$ Drug Deliv Rev (2007) 59:1073-83. doi:10.1016/j.addr.2007.07.003

177. Rogler G, Brand K, Vogl D, Page S, Hofmeister R, Andus T, et al. Nuclear factor kappaB is activated in macrophages and epithelial cells of inflamed intestinal mucosa. Gastroenterology (1998) 115:357-69. doi:10.1016/ S0016-5085(98)70202-1

178. Lewis K, Lutgendorff F, Phan V, Söderholm JD, Sherman PM, McKay DM. Enhanced translocation of bacteria across metabolically stressed epithelia is reduced by butyrate. Inflamm Bowel Dis (2010) 16:1138-48. doi:10.1002/ ibd. 21177

179. Smyth D, McKay CM, Gulbransen BD, Phan VC, Wang A, McKay DM. Interferon-gamma signals via an ERK1/2-ARF6 pathway to promote bacterial internalization by gut epithelia. Cell Microbiol (2012) 14:1257-70. doi:10.1111/j.1462-5822.2012.01796.x
180. Saitoh T, Fujita N, Jang MH, Uematsu S, Yang BG, Satoh T, et al. Loss of the autophagy protein Atg16L1 enhances endotoxin-induced IL-1beta production. Nature (2008) 456:264-8. doi:10.1038/nature07383

181. Kuballa P, Huett A, Rioux JD, Daly MJ, Xavier RJ. Impaired autophagy of an intracellular pathogen induced by a Crohn's disease associated ATG16L1 variant. PLoS One (2008) 3:e3391. doi:10.1371/journal.pone.0003391

182. Elliott TR, Hudspith BN, Rayment NB, Prescott NJ, Petrovska L, HermonTaylor J, et al. Defective macrophage handling of Escherichia coli in Crohn's disease. J Gastroenterol Hepatol (2015) 30:1265-74. doi:10.1111/jgh.12955

183. Cadwell K, Patel KK, Komatsu M, Virgin HW IV, Stappenbeck TS. A common role for Atg16L1, Atg5 and Atg7 in small intestinal Paneth cells and Crohn disease. Autophagy (2009) 5:250-2. doi:10.4161/auto.5.2.7560

184. Deuring JJ, Fuhler GM, Konstantinov SR, Peppelenbosch MP, Kuipers EJ, de Haar C, et al. Genomic ATG16L1 risk allele-restricted Paneth cell ER stress in quiescent Crohn's disease. Gut (2014) 63:1081-91. doi:10.1136/ gutjnl-2012-303527

185. Parkes M, Barrett JC, Prescott NJ, Tremelling M, Anderson CA, Fisher SA, et al. Sequence variants in the autophagy gene IRGM and multiple other replicating loci contribute to Crohn's disease susceptibility. Nat Genet (2007) 39:830-2. doi:10.1038/ng2061

186. McCarroll SA, Huett A, Kuballa P, Chilewski SD, Landry A, Goyette P, et al. Deletion polymorphism upstream of IRGM associated with altered IRGM expression and Crohn's disease. Nat Genet (2008) 40:1107-12. doi:10.1038/ ng.215

187. Cabrera S, Fernández AF, Mariño G, Aguirre A, Suárez MF, Español Y, et al. ATG4B/autophagin-1 regulates intestinal homeostasis and protects mice from experimental colitis. Autophagy (2013) 9:1188-200. doi:10.4161/ auto. 24797

188. Wehkamp J, Wang G, Kübler I, Nuding S, Gregorieff A, Schnabel A, et al. The Paneth cell alpha-defensin deficiency of ileal Crohn's disease is linked to Wnt/Tcf-4.J Immunol(2007) 179:3109-18.doi:10.4049/jimmunol.179.5.3109

189. Gardet A, Benita Y, Li C, Sands BE, Ballester I, Stevens C, et al. LRRK2 is involved in the IFN-gamma response and host response to pathogens. J Immunol (2010) 185:5577-85. doi:10.4049/jimmunol.1000548

190. Liu TC, Naito T, Liu Z, VanDussen KL, Haritunians T, Li D, et al. LRRK2 but not ATG16L1 is associated with Paneth cell defect in Japanese Crohn's disease patients. JCI Insight (2017) 2:e91917. doi:10.1172/jci.insight.91917

191. Zhang Q, Pan Y, Yan R, Zeng B, Wang H, Zhang X, et al. Commensal bacteria direct selective cargo sorting to promote symbiosis. Nat Immunol (2015) 16:918-26. doi:10.1038/ni.3233

192. Rocha JD, Schlossmacher MG, Philpott DJ. LRRK2 and Nod2 promote lysozyme sorting in Paneth cells. Nat Immunol (2015) 16:898-900. doi:10.1038/ ni. 3255

Conflict of Interest Statement: The authors declare that the research was conducted in the absence of any commercial or financial relationship that could be constructed as a potential conflict of interest.

Copyright (c) 2018 Wang, Shao, Zhao, Fang, Gu, Miao, Li and Bai. This is an openaccess article distributed under the terms of the Creative Commons Attribution License (CC BY). The use, distribution or reproduction in other forums is permitted, provided the original author(s) and the copyright owner are credited and that the original publication in this journal is cited, in accordance with accepted academic practice. No use, distribution or reproduction is permitted which does not comply with these terms. 